IJ§ER

ISSN: $2149-5939$
International Journal of Social Sciences and Education Research

Online, http://dergipark.gov.tr/ijsser

Volume: 3(2), 2017

\title{
Elit güreşçilerde uygulanan aerobik ve anaerobik antrenman programı- nın vücut kompozisyonu üzerine etkileri
}

\section{The effects of aerobic and anaerobic training programs applied to elite wrestlers on body composition}

\author{
Nurcan Demirel ${ }^{1} \quad$ Serhat Özbay ${ }^{2} \quad$ Fatih Kaya $^{3} \quad$ Metin Bayram $^{4}$
}

Received Date: $01 / 09$ / 2016

Accepted Date: 15 / $01 / 2017$

$\ddot{O} z$

Bu çalışmanın amacı; elit güreşçilerde uygulanan aerobik ve anaerobik antrenman programının, vücut kompozisyonu üzerine etkilerini araștırmaktır. Araștırmaya katılan, yaș ortalaması (deney; $15.20 \pm 4.61, n=10$, kontrol; $15.90 \pm 2.08, n=10)$ olan, 20 elit güreşçi öğrenci, rastgele yöntemle 10 kişilik iki gruba ayrıld. Deney grubuna 8 hafta devam eden, hafta da 6 gün "bir gün aerobik-bir gün anerobik" olmak üzere antrenman prensiplerine uygun olarak belirlenen, kuvvet ve dayanıklılık antrenman programı uygulandı. Kontrol grubu ise normal rutin güreş teknik antrenmanina devam etti. Deney grubundan ve kontrol grubundan 8 haftalı antrenman periyodu öncesinde ve 8 haftalık egzersiz periyodu sonlandıktan sonra, vücut analizi ölçümleri alındı (Tanita-TBF 300A). Çalışmanın sonuçlarına göre; deney grubunun beden kompozisyonu göstergelerinden empedans, beden yă̆ yüzdesi, yă̆ kütlesi, öntestten son teste anlamlı olarak azalırken, yağsız beden kütlesi ve toplam vücut suyu anlamlı olarak artmıştır $(p<0.05)$. Vücut ağırlı̆̆l, beden kütle indeksi ve bazal metabolik oranda anlamlı bir değişim olmamıștır $(p>0.05)$. Kontrol grubunun ise, beden kompozisyonu göstergelerinden vücut ağırlı̆̆l, yağstz beden kütlesi ve toplam vücut suyu değerleri öntestten sonteste anlaml olarak artmıştır $(p<0.05)$. Beden kitle indeksi, bazal metabolik oran, empedans, beden yă̆ yüzdesi ve yă̆ kütlesinde anlamlı bir değişim olmamıştır ( $p>0.05)$. Sonuç olarak; her iki gruptaki öntest ve sontest değişimleri benzer olup, gruplar arasında anlamlı bir farklılık bulunamamıştır ( $p>0.05)$. İstatistiksel analizlerde grup içi karşılaştırmalar için eş-örneklem t testi (paired-samples t test), gruplararası karşılaştırmalar için bağımsız örneklem $t$ testi (independent sample t test) kullanıldl. Anlamlılık seviyesi $p<0.05$ olarak belirlendi. Tüm değerler için ortalama ve standart sapma kullanıldı. Sonuç olarak; bu çalışma rutin olarak egzersizine devam eden kontrol grubu sporcularında anlamlı bir değişiklik getirmezken, şekli ve şiddeti değişen antrenman programının ise, deney grubunda anlaml farklılıklar meydana getirdiğini ortaya koymuștur. Deney grubundaki olumlu değişimleri daha belirgin olsa da her iki grup arasında anlamlı bir değişim bulunamamıştır.

Anahtar sözcükler: Güres, aerobik egzersiz, anerobik egzersiz beden kompozisyonu

\begin{abstract}
The purpose of this study is to analyse the effects of aerobic and anaerobic training programs applied to elite wrestlers on body composition. 20 elite wrestler student whose average age is (experiment group; 15.20 \pm 4.61, $n=10)$, control group; $15.90 \pm 2.08, n=10)$ participated to the study and they were divided into two groups randomly. Strength and durability training program based on "one day aerobic, one day anaerobic" principles was applied to the experiment group six days in a week for eight weeks. Control group continued to do normal routine wrestling technical training. Before and after eight weeks training program body analyse measurements were taken from experiment and control group. (Tanita) According to the results of the study, impedance, body fat percentage and fat mass from body composition indicators of experiment group significantly decreased from pretest to posttest while fat-free body mass and whole body water increased significantly. $(p<0.05)$. There was no significant difference in body weight, body mass index and bazal metabolic rate. ( $p>0.05)$. However, for control group; body weight, fat-free body mass and whole body water values from body mass index indicators of control group significantly increased from pretest to posttest. $(p<0.05)$. There was no significant difference in body mass index, bazal metabolic rate, impadence, body fat percentage and fat mass ( $p>0.05)$. As a result, pretest and posttest cahangings are similar in both groups and there was no significant difference between two groups. $(p>0.05)$. Paired-samples $t$ test was used for in-group comparison and independent sample t test was used for intergroup comparisons in
\end{abstract}

\footnotetext{
${ }^{1}$ Atatürk Üniversitesi, Spor Bilimleri Fakültesi, Spor Sağlık Bilimleri Anabilim Dalı, Erzurum, Türkiye. ${ }^{2}$ Atatürk Üniversitesi, Spor Bilimleri Fakültesi, Spor Sağlık Bilimleri Anabilim Dalı, Erzurum, Türkiye. ${ }^{3}$ Erzincan Üniversitesi, Eğitim Fakültesi, Beden Eğitimi ve Spor Öğretmenliği, Erzincan, Türkiye.

${ }^{4}$ Ağrı İbrahim Çeçen Üniversitesi, Beden Eğitimi ve Spor Yüksekokulu, Ağrı, Türkiye.
} 
Demirel, N. Özbay, S., Kaya, F., Bayram, M. (2017). Elit güreşçilerde uygulanan aerobik ve anaerobik antrenman programının vücut kompozisyonu üzerine etkileri. International Journal of Social Sciences and Education Research, 3(1), 675-682.

statistical analyses. Significance level was determined as $p<0.05$. Average and standard deviation were used for all values. As a result, this study did not reveal a significant difference on control group athletes who practice regularly. However, training program which has variable types and volume made significant differences on experiment group. There was no significant difference between two groups even though positive changings in experiment group were clearer.

Keywords: Wrestling, aerobic exercise, anaerobic exercise, body composition

\section{Giriş}

Günümüz dünyasında teknolojik gelişmelerin de etkisiyle insanların hareketsiz yaşamı ve kötü beslenmeyi alışkanlık haline getirmeleri aşırı kiloya bağlı olarak çağın belası diye adlandırılan obezite denen durum ölümcül sonuçlar doğurmaya başlamıştır. Bugün bütün Dünyanın birinci önceliği obeziteyle mücadeledir. Kötü yaşam ve yanlış beslenmeye bağlı olarak gelişen obezite, kardiyovasküler sistemi de olumsuz yönde etkilemektedir. Bütün bu olumsuzluklar insan neslinin bugününü ve yarınını ciddi şekilde tehdit etmektedir. Vücuttaki olumsuz yağlanmayı önlemek için düzenli egzersizi içinde barındıran hareketli yaşam zaruri hal almıştır.

Hareketsiz, sedanter bir yaşam tarzı enerji dengesinin bozulmasına dolayısıyla obezitenin oluşmasına neden olabilmektedir. Obezite, yağ oranının fazlalığı ve endomorfi oranının yüksekliği ile karakterizedir. Özellikle vücut ağırlığının normal sınırları aşması durumunda birçok ciddi sağlık probleminin yanı sıra fiziksel iş kapasitesinde de azalma görülebilmektedir (Carter ve Heath,1990; Cusumano ve Thompson , 1997; Erkan, 1998). Sağlı problemlerin yanı sıra günümüz de her yaşta insanın özelikle de genç neslin önemle üzerinde durduğu konulardan biri fiziksel görünüştür. Fiziksel zayıflığın ya da güzel görünmenin kültürel bir değer olarak yansıtıldığı reklam, magazin ve TV programlarında fiziksel görünüş çoğu zaman bireyin düşünce, davranış ve başarılarının önüne geçebilmektedir. Sosyal olarak kabul edilmiş değerler gözden geçirildiğinde kadınlarda inceliğin erkeklerde ise kaslı vücut yapısının tercih edildiği görülmektedir (Baştuğ vd., 2011; Çolakoğlu ve Karacan, 2006).

Aşı1rı yağlanma ve obezite hem psikolojik hem de fizyolojik bir sorun haline gelmiştir.

Bu sağlık risklerine göre en etkili egzersiz türleri yürüyüş, koşu, dağ yürüyüşü, bisiklet, kürek, yüzme gibi aerobik kapasiteyi arttıran çalışmalardır. Özellikle şişmanlık, kardiyovasküler hastalıklar ve kemiklerde deformasyon gibi sağlık problemlerinin giderilmesinde aerobik egzersizlerle yüksek verim elde edilebilir (Cusumano ve Thompson, 1997; Zorba, 1999). Yüksek yoğunluktaki egzersiz süresince yağlar mobilize olarak hidrolize olur ve enerji sağlarlar. Yapılan çalışmalar $\mathrm{VO}^{2}$ maks' 1 \% $\%$ 5'i düzeyinde yapılan egzersiz süresince yağ oksidasyonunun belirgin derecede arttığını göstermektedir (Sınırkavak vd., 2004), (Smith vd, 2000), (Wolfe, 1998). Düzenli egzersiz programları vücut kompozisyonlarını değiştirir. Kardiyorespiratuvar antrenmanlar ve ağırlık antrenmanları vücut ağırlığını düşürür. Aerobik dayanıklılık antrenmanlarının vücut kompozisyonlarını belirleyici etkisi üzerine birçok çalışma bulunmaktadır (Galliven vd.,1997; Kannin ve Phil, 2005; Sınırkavak vd., 2004). Yapılan çalışmalar incelendiğinde daha çok aerobik antrenman programlarının veya tek tip antrenmanların vücut kompozisyonu üzerine etkileri incelendiği görülmektedir. Bu yüzden yapılan bu çalışmada aerobik ve anaerobik antrenman programlarının antrene sporcularda vücut kompozisyonuna olan etkisini incelenmek amaçlanmıştır. 
Demirel, N. Özbay, S., Kaya, F., Bayram, M. (2017). The effects of aerobic and anaerobic training programs applied to elite wrestlers on body composition. International Journal of Social Sciences and Education Research, 3(1), 675-682.

\section{Materyal ve Metot}

Yapılan çalışmaya yaşları 12-25 arası 20 gönüllü elit güreşçi katıldı. Sporcular yazılı ve sözlü olarak çalışmalar hakkında bilgilendirildiler. Sporcular rastgele yöntemle 10 kişilik deney ve kontrol grubu olmak üzere iki gruba ayrıldılar. Deney grubuna 8 haftalık bir gün aerobik bir gün anaerobik olmak üzere haftada 6 gün antrenör eşliğinde antrenman programı uygulanırken, kontrol grubu rutin haftalık güreş antrenmanını yapmaya devam etti. Sporculara uygulanan egzersizin öncesi ve sonrasında vücut kompozisyon analiz cihazıyla beden kütle indeksi (BMI), BMR (kcal), Impedance $(\Omega)$, Fat (\%), Fat mass, FFM (kg), TBW (kg) ölçümleri alındı. Bu ölçümler her iki grup arasında antrenman programlarının etkisini belirlemek amacıyla analiz edildi.

\subsection{Istatistiksel analizler}

İstatistik analizleri SPSS 20.0 programı (SPSS-Chicago, IL, United States) kullanılarak yapıldı. Parametrelerin normal dağılıma uygunluğu Kolmogorov-Smirnov testi ile değerlendirildi. Normal dağılım gösteren parametreler için ortalama \pm standart sapma, normal dağılmayan parametreler için medyan ve minimum-maksimum değerleri verildi. Antrenman öncesi ve sonrası değerlerin karşılaştırılmasında bağımlı örneklemlerde t-testi (paired t-test) kullanıldı. Egzersiz sonrası değerler, Dill ve Costill'in önerileri doğrultusunda egzersize bağlı plazma volümünde azalmaya göre hesaplandı (Dill ve Costill, 1974; Kaynar vd., 2016).

\section{Bulgular}

Deney ve kontrol grubunun fiziksel özellikleri Tablo 1'de belirtilmiştir.

Tablo 1. Deney ve kontrol grubunun fiziksel özellikleri. Ort (Ss)

\begin{tabular}{lccc}
\hline \hline Grup & Yaş (yıl) & Boy (cm) & Ăğırlık (kg) \\
\hline $\begin{array}{l}\text { Deney } \\
\mathrm{n}=10\end{array}$ & $15.20(4.61)$ & $157.10(15.98)$ & $52.57(18.74)$ \\
\hline $\begin{array}{l}\text { Kontrol } \\
\mathrm{n}=10\end{array}$ & $15.90(2.08)$ & $166.20(12.80)$ & $56.84(11.14)$ \\
\hline \hline
\end{tabular}

Deney grubunun ön test ve son test vücut kompozisyon değişimleri Tablo 2'de belirtilmiştir. Deney grubunun vücut kompozisyonu göstergelerinden empedans, beden yağ yüzdesi, yağ kütlesi, yağsız beden kütlesi ve toplam vücut suyu değerleri öntestten sonteste anlamlı olarak değişmiştir $(p<0.05)$. Vücut ağırlığı, beden kütle indeksi ve bazal metabolik oranda anlamlı bir değişim olmamıştır ( $\mathrm{p}>0.05$ ). Buna göre deney grubunun empedans, beden yağ yüzdesi ve yağ kütlesi öntestten son teste anlamlı olarak azalırken, yağsız beden kütlesi ve toplam vücut suyu anlamlı olarak artmıştır. 
Demirel, N. Özbay, S., Kaya, F., Bayram, M. (2017). Elit güreşçilerde uygulanan aerobik ve anaerobik antrenman programının vücut kompozisyonu üzerine etkileri. International Journal of Social Sciences and Education Research, 3(1), 675-682.

Tablo 2. Deney grubunda öntestten sonteste vücut kompozisyonundaki değişimleri

\begin{tabular}{|c|c|c|c|c|}
\hline & & Ort (Ss) & $\mathrm{sd}$ & $\mathrm{t}$ \\
\hline \multirow{2}{*}{ Vücut ağırlığı (kg) } & Öntest & $52.57(18.74)$ & \multirow{2}{*}{9} & \multirow{2}{*}{-1.191} \\
\hline & Sontest & $52.96(18.80)$ & & \\
\hline \multirow{2}{*}{ BMI (kg/boy $\left.{ }^{2}\right)$} & Öntest & $20.61(3.21)$ & \multirow{2}{*}{9} & \multirow{2}{*}{-.201} \\
\hline & Sontest & $20.64(3.18)$ & & \\
\hline \multirow{2}{*}{ BMR (kcal) } & Öntest & $1556.50(268.09)$ & \multirow{2}{*}{9} & \multirow{2}{*}{-1.356} \\
\hline & Sontest & $1563.70(269.58)$ & & \\
\hline \multirow{2}{*}{ Impedance $(\Omega)$} & Öntest & $484.00(37.54)$ & \multirow{2}{*}{9} & \multirow{2}{*}{$2.558 *$} \\
\hline & Sontest & $471.20(44.49)$ & & \\
\hline \multirow{2}{*}{ Fat $(\%)$} & Öntest & $12.36(4.40)$ & \multirow{2}{*}{9} & \multirow{2}{*}{$6.045 * *$} \\
\hline & Sontest & $11.54(4.65)$ & & \\
\hline \multirow{2}{*}{ Fat mass } & Öntest & $6.99(4.88)$ & \multirow{2}{*}{9} & \multirow{2}{*}{$4.841 * *$} \\
\hline & Sontest & $6.65(4.91)$ & & \\
\hline \multirow{2}{*}{ FFM (kg) } & Öntest & $45.58(14.34)$ & \multirow{2}{*}{9} & \multirow{2}{*}{$-2.389 *$} \\
\hline & Sontest & $46.31(14.48)$ & & \\
\hline \multirow{2}{*}{ TBW (kg) } & Öntest & $33.28(10.54)$ & \multirow{2}{*}{9} & \multirow{2}{*}{$-2.545^{*}$} \\
\hline & Sontest & $33.80(10.56)$ & & \\
\hline
\end{tabular}

Kontrol grubunun öntest ve sontest vücut kompozisyon değişimleri Tablo 3'de belirtilmiştir.

Tablo 3. Kontrol grubunda öntestten sonteste vücut kompozisyonundaki değişimler

\begin{tabular}{|c|c|c|c|c|}
\hline & & Ort (Ss) & sd & $\mathrm{t}$ \\
\hline \multirow{2}{*}{ Vücut ağırlığı (kg) } & Öntest & $56.84(11.14)$ & \multirow{2}{*}{9} & \multirow{2}{*}{$-2.398 *$} \\
\hline & Sontest & $57.11(11.08)$ & & \\
\hline \multirow{2}{*}{ BMI (kg/boy $\left.{ }^{2}\right)$} & Öntest & $20.38(2.11)$ & \multirow{2}{*}{9} & \multirow{2}{*}{-1.238} \\
\hline & Sontest & $20.46(2.10)$ & & \\
\hline \multirow{2}{*}{ BMR (kcal) } & Öntest & $1648.00(175.83)$ & \multirow{2}{*}{9} & \multirow{2}{*}{-2.115} \\
\hline & Sontest & $1652.90(175.28)$ & & \\
\hline \multirow{2}{*}{ Impedance $(\Omega)$} & Öntest & $483.30(39.97)$ & \multirow{2}{*}{9} & \multirow{2}{*}{.858} \\
\hline & Sontest & $480.50(36.06)$ & & \\
\hline \multirow{2}{*}{ Fat $(\%)$} & Öntest & $10.03(3.98)$ & \multirow{2}{*}{9} & \multirow{2}{*}{.188} \\
\hline & Sontest & $10.01(3.95)$ & & \\
\hline \multirow{2}{*}{ Fat mass } & Öntest & $5.76(2.78)$ & \multirow{2}{*}{9} & \multirow{2}{*}{-.739} \\
\hline & Sontest & $5.80(2.85)$ & & \\
\hline \multirow{2}{*}{ FFM (kg) } & Öntest & $51.07(9.63)$ & \multirow{2}{*}{9} & \multirow{2}{*}{$-2.714^{*}$} \\
\hline & Sontest & $51.31(9.47)$ & & \\
\hline \multirow{2}{*}{ TBW (kg) } & Öntest & $37.39(7.06)$ & \multirow{2}{*}{9} & \multirow{2}{*}{$-2.714^{*}$} \\
\hline & Sontest & $37.57(6.94)$ & & \\
\hline
\end{tabular}

$* \mathrm{p}<0.05$.

Kontrol grubunun vücut kompozisyonu göstergelerinden vücut ağırlığı, yağsız beden kütlesi ve toplam vücut suyu değerleri öntestten sonteste anlamlı olarak değişmiştir $(p<0.05)$. Beden 
Demirel, N. Özbay, S., Kaya, F., Bayram, M. (2017). The effects of aerobic and anaerobic training programs applied to elite wrestlers on body composition. International Journal of Social Sciences and Education Research, 3(1), 675-682.

kütle indeksi, bazal metabolik oran, empedans, beden yağ yüzdesi ve yağ kütlesinde anlamlı bir değişim olmamıştır ( $p>0.05$ ). Buna göre kontrol grubunun vücut ağırlığ 1 , yağsız beden kütlesi ve toplam vücut suyu öntestten son teste anlamlı olarak artmıştır.

Her iki gruptaki öntest ve sontest değişimleri benzer olup, gruplar arasında anlamlı bir farklılık bulunmamıştır ( $\mathrm{p}>0.05)$.

\section{Tartışma ve sonuç}

Bu çalışmada deney grubunun vücut kompozisyonu göstergelerinden empedans, beden yă yüzdesi, yağ kütlesi, yağsız beden kütlesi ve toplam vücut suyu değerleri öntestten sonteste anlamlı olarak değişmiştir $(\mathrm{p}<0.05)$. Vücut ağırlığı, beden kütle indeksi ve bazal metabolik oranda anlamlı bir değişim olmamıştır ( $>0.05$ ). Buna göre deney grubunun empedans, beden yağ yüzdesi ve yağ kütlesi öntestten sonteste anlamlı olarak azalırken, yağsız beden kütlesi ve toplam vücut suyu anlamlı olarak artmıştır. Kontrol grubunun vücut kompozisyonu göstergelerinden vücut ağırlığı, yağsız beden kütlesi ve toplam vücut suyu değerleri öntestten sonteste anlamlı olarak değişmiştir $(p<0.05)$. Beden kütle indeksi, bazal metabolik oran, empedans, beden yağ yüzdesi ve yağ kütlesinde anlamlı bir değişim olmamıştır ( $>0.05$ ). Buna göre kontrol grubunun vücut ağırlığı, yağsız beden kütlesi ve toplam vücut suyu öntestten sonteste anlamlı olarak artmıştır. Her iki gruptaki öntest ve sontest değişimleri benzer olup, gruplar arasında anlamlı bir farklılık bulunmamıştır ( $\mathrm{p}>0.05)$.

Deney grubunda gözlemlenen değişimler daha belirgin olsa da kontrol grubuyla kıyaslandığında değişimlerin benzerlik taşıdığı görülmektedir. Bunun sonucu olarak da kontrol grubundaki sporcularında elit sporcu olmaları ve daha önce uygulanan egzersiz programlarının etkilerinin devam etmesi gösterilebilir.

Votruba vd. (2000) derlemelerinde dayanıklılık egzersizi hariç ne egzersiz tipinin ne de miktarının asla kilo kaybına çok fazla etkisinin olmadığını ifade etmişlerdir. Yaptığımız çalışmada VKİ değerinde de anlamlı bir artış meydana geldiği tespit edilmiştir. VKİ değerleri bakımından elde edilen sonuçlar da literatürle farklılık göstermektedir. Antrenman uygulamaları sonucunda bizim çalışmamızla örtüşen VKI'de değişikliğin olmadığını gösteren sonuçlar (A ğırbaş vd., 2009; Büyükyazı, 2008; Savucu vd., 2006; Uğraş vd., 2002) olduğu gibi VKİ değerlerinde azalmaların olduğunu gösteren sonuçlarda (Çolakoğlu ve Karacan, 2006), (Çolakoğlu ve Şenel 2003; Lakka vd., 2004; Wong vd., 2008; Yalın vd., 2001) mevcuttur. VKI'deki bu artışın vücut ağırlığındaki artışa paralel olarak meydana geldiği düşünülmektedir. Karakaş ve ark. (2005) yaptıkları çalışmada yaptığımız çalışmayla örtüşen herhangi bir diyet olmaksızın sadece düzenli egzersizle yağ kütlesinde azalma olduğunu, yağsız vücut kütlesinde ise artış olduğunu belirlemişlerdir. Yapılan egzersizler sonucunda vücut yağ kütlesinin azaldığı ve bu azalmanın derecesinin yapılan egzersizin tipine, şiddetine ve sıklığına bağlı olduğu ifade edilen çalışmalar vardır (Akgün 1993; Stamford, 1983). Birçok çalışmada (Çolakoğlu ve Şenel, 2003; Karakaş vd., 2005; Lakka vd., 2004) yapılan egzersizler sonucunda vücut yağ kütlesinde azalmalar tespit edilirken Wong et al. (2008) yaptıkları çalışmada vücut yağ kütlesinde anlamlı bir farklılık bulamamışlar, fakat yağsız vücut kütlesinin arttığını belirlemişlerdir. Yapılan bir araştırmada, antrenmanlarla yüksek miktarda enerji harcaması sonucunda vücut yağ yüzdelerinde yaptığımız çalışmayla örtüşen bir şekilde azalmalar meydana geldiği ifade edilmektedir (Stamford, 1983). Konu ile ilgili yapılan araştırmalar incelendiğinde birçok çalışmada VYY'de azalmalar meydana geldiği tespit edilmiştir (Ateş 
Demirel, N. Özbay, S., Kaya, F., Bayram, M. (2017). Elit güreşçilerde uygulanan aerobik ve anaerobik antrenman programının vücut kompozisyonu üzerine etkileri. International Journal of Social Sciences and Education Research, 3(1), 675-682.

vd., 2007; Çolakoğlu ve Şenel, 2003; Gökdemir vd., 2007; Lakka vd., 2004; Saka vd., 2008; Uğraş vd., 2002). Sağlıklı sporcular üzerinde yapılan bir çalışmada, uzun süreli ve tekrarlı egzersizlerin yoğunluğuna bağlı olarak hem hücre içi hem de hücre dışı sıvıda kronik hiperhidrasyon meydana geldiği tespit edilmiştir (Fellmann vd., 1999). Bir başka çalışmada egzersiz yapan Beden Eğitimi ve Spor Yüksekokulu öğrencilerinin hücre içi sıvı düzeylerinde artış meydana geldiğini belirlemişlerdir (Karakaş S ve ark. 2005). Ayrıca hücre içi sıvısındaki bu artışın YVK'ndeki artışa paralel olarak geliştiğini de ifade etmişlerdir (Fellmann vd., 1999; Votruba vd., 2000).

Bulunan bu sonuçlar çalışmamızı destekler niteliktedir. Yapılan çalışmanın sonucunda egzersizin çeşidi ve şiddeti ne olursa olsun fiziksel aktivitenin vücutta belli değişimlere yol açtı̆ğ, aerobik ve anaerobik egzersiz programlarının bir arada uygulanması rutin güreş antrenmanına göre nispeten daha iyi sonuçlar doğursa da antrenman programlarının etkileri arasında anlamlı bir değişim bulunamamıştır.

\section{Kaynakça}

Ağırbaş Ö, Kishalı NF, Çolak, M. (2009). Müsabaka Döneminde Erkek Hentbol Oyuncularının Vücut Kompozisyonlarının Kan Lipid ve Lipoprotein Düzeyleri Üzerine Etkisi. Erzincan Üniversitesi Fen Bilimleri Enstitüsü Dergisi 2.2: 133-151.

Akgün N. (1993). Egzersiz Fizyolojisi. 4. Baskı İzmir: Ege Üniversitesi Matbaası.

Ateş M, Demir M, Ateşoğlu U. (2007). Polimetrik Antrenmanın 16-18 Yaş Grubu Erkek Futbolcuların Bazı Fiziksel ve Fizyolojik Parametreleri Üzerine Etkisi. Niğde Üniversitesi Beden Eğitimi ve Spor Bilimleri Dergisi, 1(1), 4-15.

Baştuğ G, Akandere M, Yıldız H. (2011). Sedanter Genç Bayanlarda Aerobik Egzersizin Vücut Kompozisyonu ve Kendini Fiziksel Tanımlama Değerlerine Etkisi. Spor ve Performans Araştırmaları Dergisi 2.2.

Büyükyazı G, Ulman C, Taneli F, Aksoy D, T1kız H. (2008). Effects of Walking on Serum Lipids, MMP9 And TIMP-1 in Post-Menopausal Women. 10th International Sport Congress, Bolu, Turkey.

Carter JEL, Heath BH. (1990). Somatotyping-Development and Application. Cambridge University Press.

Cusumano DL, Thompson JK. (1997). Body Image and Body Shape Ideals in Magazines, Exposure, Awareness and Internalization. Sex Roles. 37: 701-721.

Çolakoğlu F. Karacan S. (2006). Genç Bayanlar ile Orta Yaş Bayanlarda Aerobik Egzersizin Bazı Fizyolojik Parametrelere Etkisi. Kastamonu Eğitim Dergisi. Cilt:14 No:1. 277-284.

Çolakoğlu F, Şenel Ö. (2003). Sekiz Haftalık Aerobik Egzersiz Programının Sedanter Orta Yaşlı Bayanların Vücut Kompozisyonu ve Kan Lipidleri Üzerindeki Etkileri. Spormetre. 13(1): 57-61.

Dill DB, Costill DL. (1974). Calculation of Percentage Changes in Volumes of Blood, Plasma, and Red Cells in Dehydration. J Appl Physiol 37:247-248.

Erkan N. (1998). Yaşam Boyu Spor. Bağırgan Yayımevi, Ankara.

Fellmann N, Ritz P, Ribeyre, J, Beaufrere B, Delaitre M, Coudert J. (1999). Intracellular Hyperhidration İnduced by A 7-Day Andurance Race. Eur J Appl Physiol Occup Physio,l 80:353-359.

Galliven EA, Singh A, Michelson D. (1997). Hormonal and Metabolic Responses to Exercise Across Time of Day Andmenstrual Cycle Phase. J Appl Physiol; 85:1822-1831.

Gökdemir K, Koç H, Yüksel O. (2007). Aerobik Antrenman Programının Üniversite Öğrencilerinin Bazı Solunum ve Dolaşım Parametreleri ile Vücut Yağ Oranı Üzerine Etkisi. Egzersiz Çevrimiçi Dergisi, 1(1): 45-49.

Kannin B, Phil D. (2005). The effect of short-vs. long-bout exercise on mood, VO2max, and percent body fat. Preventive Medicine; 40:92-98. 
Demirel, N. Özbay, S., Kaya, F., Bayram, M. (2017). The effects of aerobic and anaerobic training programs applied to elite wrestlers on body composition. International Journal of Social Sciences and Education Research, 3(1), 675-682.

Karakaş S, Taşer F, Yıldız Y, Köse H. (2005). Tıp Fakültesi ve Spor Yüksek Okulu Öğrencilerinde Biyoelektriksel Empedans Analiz (BIA) Yöntemi ile Vücut Kompozisyonlarının Karşılaştırılması. ADÜ Tlp Fakültesi Dergisi, 6(3):5-9.

Kaynar Ö, Öztürk N, Kıyıcı, F, Baygutalp NK, Bakan E. (2016). Kick Boks Sporcularında Kısa Süreli Yoğun Egzersizin Karaciğer Enzimleri ve Serum Lipit Düzeyleri Üzerine Etkileri. Dicle Medical Journal/Dicle Tip Dergisi, 43(1).

Lakka HM, Tremblay A, Després JP, Bouchard C. (2004). Effects of Long-Term Negative Energy Balance With Exercise on Plasma Lipid and Lipoprotein Levels in İdentical Twins. Atherosclerosis, 172: 127133.

Saka, T, Yıldız Y, Tekbaş ÖF, Aydın T. (2008). Genç Erkeklerde Spor Okulu Eğitim Programının Bazı Antropometrik ve Fonksiyonel Testler Üzerine Etkisi. Niğde Üniversitesi Beden Ĕgitimi ve Spor Bilimleri Dergisi, 2(1).

Savucu Y, Sirmen B, İnal S, Karahan M, Erdemir İ. (2006). Zihinsel Engelli Bireylerde Basketbol Antrenmanının Fiziksel Uygunluk Üzerine Etkilerinin Belirlenmesi. Fırat Üniversitesi Sağlık Bilimleri Dergisi, 20(2): 105-113.

Sınırkavak G, Dal U, Çetinkaya Ö. (2004). Elit Sporcularda Vücut Kompozisyonu ile Maksimal Oksijen Kapasitesi Arasındaki İlişki. Cumhuriyet Üniversitesi Tıp Fakültesi, 171-176.

Smith T, Smith B, Davis M. (2000). Predictors of Physical Fitness in a Collage Sample. Percept Mat Skills 1:1009-10.

Stamford B. (1983). The Results of Aerobic Exercise. The Physician and Sport Medicine, 1(9):145.

Uğraş A, Özkan H, Savaş S. (2002). Bilkent Üniversitesi Futbol Takımının 10 Haftalık Ön Hazırlık Sonrasındaki Fiziksel ve Fizyolojik Karekteristikleri. G. U. Gazi Eğitim Fakültesi Dergisi, 22(1): 241-252.

Votruba SB, Horvitz MA, Schoeller DA. (2000). The Role of Exercise in the Treatment of Obesity. Nutrition, 16:179-188.

Wolfe RR. (1998). Fat Metabolism in Exercise. Adir Exp Bial 441:147-56.

Wong PCH, Chia MYH, Tsou IYY, Wansaicheong, GKL, Tan B, Wang JCK, Tan J, Kim CG, Boh G, Lim D. (2008). Effects of A 12-Week Exercise Training Programme on Aerobic Fitness, Body Composition, Blood Lipids and C-Reactive Protein in Adolescents with Obesity. Ann Acad Med Singapore, 37: 28693.

Yalın S. Gök H. Toksöz R. (2001). Sedanter Bireylerde Kısa Dönem Düzenli Egzersiz-Diyet Programının Lipid Profili Üzerindeki Etkileri. Ana Kar Der, 1: 179-188.

Zorba E. (1999). Herkes İçin Spor ve Fiziksel Uygunluk. Meyir Matbaacılı, Ankara. 
Demirel, N. Özbay, S., Kaya, F., Bayram, M. (2017). Elit güreşçilerde uygulanan aerobik ve anaerobik antrenman programının vücut kompozisyonu üzerine etkileri. International Journal of Social Sciences and Education Research, 3(1), 675-682.

\section{Extended abstract in English}

In our modern world, with the effect of technological movements, inactive life and malnutrition of people have caused obesity which is also called one of the worst diseases of the century. Obesity has begun bringing fatal problems depending on over-weight. Today, first priority of the whole world is fighting against obesity. Obesity, which develops inactive life and malnutrition, affects cardiovascular system negatively as well. All these negations threaten today and future of human generation seriously. In order to prevent negative lipoidosis in body it is necessary to have a life style which contains regular exercises. An inactive and sedentary life style can cause to collapse energy balance accordingly obesity.

Obesity is characterised by overflow of fat rate and high incidence of endomorphy. In addition to various serious health problems, decrease in physical working capacity might be seen in especially when body weight exceeds normal limits (Carter and Heath 1990; Cusumano and Thompson, 1997; Erkan, 1998). Besides health problems, one of the most significant issues, which people of all ages especially young generation urge upon, is physical appearance. When values accepted socially are handled it is observed that women prefer slimness and men prefer muscular body (Baştuğ et al. 2011; Çolakoğlu and Karacan 2006).

Over lipoidosis and obesity have become both psychological and physiological problem. According to these health risks the most efficient exercises are walking, running, trekking, cycling, rowing and swimming which increase aerobic capacity. Aerobic exercises can be very effective on removing health problems like obesity, cardiovascular illnesses and deformation in bones. When previous studies are analyzed, it is seen that mostly effects of aerobic training programs or monotype training on body composition have been studied. For that reason, in this study, it is aimed to analyze effects of aerobic and anaerobic training programs on body composition in trained athletes.

The purpose of this study is to analyse the effects of aerobic and anaerobic training programs applied to elite wrestlers on body composition. 20 volunteers aged between 12 and 25 elite wrestlers attended to the study. Athletes were informed about the study verbally and written. Athletes were divided in to two groups of ten as experimental and control randomly. An eight week one day aerobic and one day anaerobic program was applied to experimental group while athletes in control group continue to do their weekly training program. Before and after the program applied to the athletes, body mass index (BMI), BMR (kcal), Impedance $(\Omega)$, Fat $(\%)$, Fat mass, FFM $(\mathrm{kg})$, TBW $(\mathrm{kg})$ measurements were taken by body composition analyser (Tanita-TBF 300A). These measurements were analysed in order to define the effect of training programs in two groups.

As a result, pretest and posttest changings are similar in both groups and there was no significant difference between two groups. ( $p>0.05$ ). Paired- samples $t$ test was used for in-group comparison and independent sample $t$ test was used for intergroup comparisons in statistical analyses. Significance level was determined as $\mathrm{p}<0.05$. Average and standard deviation were used for all values. Even though changes observed in experimental group are more significant, two groups have similar differences. As a result of this it can be said that athletes in control group are elite athletes and effects of previous training programs have continued.

These gained results support our study. As a result of the study, it is found out that exercise causes certain changes in body regardless of its variety and volume. Even though applying aerobic and anaerobic training programs together have better results than routine wrestling training programs, there is no significant change between effects of training programs. 